\title{
Multidisciplinary collaboration: the key to advancing lung transplantation outcomes
}

\author{
Archer Kilbourne Martin $^{1}$ (D) $\cdot$ Ashley Virginia Fritz ${ }^{2} \cdot$ Harish Ramakrishna $^{2}$
}

Received: 10 March 2021 / Accepted: 16 March 2021 / Published online: 29 April 2021

(C) Indian Association of Cardiovascular-Thoracic Surgeons 2021

Scientific inquiry into lung transplantation began with a single physician, Vladimir Demikhov, who pursued the initial investigations in the isolated setting of the 1940s Soviet Union [1]. As history progressed, improvement in outcomes was characterized by multidisciplinary team coordination, from the work of the Toronto Group leading to the first successful long-term lung transplant to the formation of the International Society for Heart and Lung Transplantation (ISHLT) in the 1980s [2]. The annual publication of the ISHLT Registry, which collects the aggregate reported data of global cardiothoracic transplant outcomes, combined with the multidisciplinary and international collaboration facilitated by the organization has led to improvement in lung transplantation outcomes over the past three decades [3]. As we examine the topic of lung transplantation in this issue of the Indian Journal of Thoracic and Cardiovascular Surgery, we can see that success in building a program is found when a comprehensive multi-faceted approach is undertaken by the transplant team.

Whereas the core of lung transplant teams has traditionally been pulmonologists and surgeons, anesthesiologists have recently emerged as the third leg of the physician team. This growth within the team has been secondary to the recognition of preoperative, intraoperative, and postoperative management being shown to impact overall outcomes including the development of primary graft dysfunction (PGD) [4]. The development of PGD remains one of the key perioperative indices we should seek to minimize secondary to its impact on short-term and long-term morbidity as well as mortality within lung transplant recipients [5]. Formation of a

Archer Kilbourne Martin

Martin.Archer@mayo.edu

1 Division of Cardiovascular and Thoracic Anesthesiology, Department of Anesthesiology and Perioperative Medicine, Mayo Clinic, 4500 San Pablo Road, Jacksonville, FL 32224, USA

2 Division of Cardiovascular and Thoracic Anesthesiology, Department of Anesthesiology and Perioperative Medicine, Mayo Clinic, Rochester, MN, USA unified treatment plan and clear communication between the various stakeholders are essential, as outcomes in lung transplantation have been shown to be affected by surgical, medical, organizational, and anesthetic factors [4].

Beyond the physician contributions from the fields of surgery, medical subspecialties, and anesthesiology, nonphysician contributions are significant, including the specialties of pharmacy, social work, physical therapy, and nutritionists [6]. Advancement in outcomes will continue if we recognize the various physician and non-physician members of the transplant team and optimize their contributions. Another aspect of optimization is recognition of not only the diversity of team member backgrounds, but also tailoring care to the diversity of end-stage lung disease (ESLD) leading to lung transplantation as well [7, 8]. Clinical, educational, and research efforts across the lung transplant team should focus on elucidating the precise differences between presenting pathologies, and preliminary literature has provided perioperative recommendations specific for patients who present with ESLD in the general categories of restrictive, obstructive, suppurative, or primary pulmonary hypertensive disease [8].

In addition to the multidisciplinary collaboration across clinical, educational, and research efforts, the importance of international perspectives cannot be overstressed. A recent example is the ISHLT international collaboration regarding organ allocation policies around the world [9]. When collaboration extends beyond our individual specialties and centers, we are able to not only assess issues from a variety of perspectives, but potentially affect global change based on our collective experience. This featured issue of the Indian Journal of Thoracic and Cardiovascular Surgery dedicated to lung transplantation examines a breadth of issues including education, surgical techniques, organizational considerations, and medical therapies from a range of international authors. May the reader remember the seminal work of individuals, such as Dr. Demikhov, and the current context of international, multidisciplinary teamwork in order to advance the lung transplantation outcomes for each of our patients. 
Acknowledgements The authors would like to thank Barbara Weisser, Mayo Clinic Academic Support Office, Scottsdale, AZ.

Funding None.

\section{Declarations}

Conflict of interest The authors have no competing interests.

Research involving human participants and/or animals Not applicable as per institutional ethical committee as the scientific information presented in paper does not fall into category of clinical trials or usage of experimental modalities.

Informed consent Not applicable.

\section{References}

1. Shoja MM, Tubbs RS, Ardalan MR, Loukas M, Phagava H, CohenGadol AA. A testimony to the history of heart and lung transplantation: English translation of Demikhov's paper, "Transplantation of the Heart, Lungs and other Organs". Int J Cardiol. 2010;143:230-4. https://doi.org/10.1016/j.ijcard.2010.02.078.

2. Martin AK, Renew JR, Jayaraman AL, Murray AW, Fritz AV, Ramakrishna H. Analysis of outcomes in lung transplantation. J Cardiothorac Vasc Anesth. 2019;33:1455-66. https://doi.org/10. 1053/j.jvca.2018.06.014.
3. Stehlik J, Edwards LB, Rowe A, et al. ISHLT International Registry for Heart and Lung Transplantation - three decades of scientific contributions. Transplant Rev (Orlando). 2013;27:38-42. https://doi. org/10.1016/j.trre.2013.01.005.

4. Martin AK, Yalamuri SM, Wilkey BJ, et al. The impact of anesthetic management on perioperative outcomes in lung transplantation. J Cardiothorac Vasc Anesth. 2020;34:1669-80. https://doi.org/10. 1053/j.jvca.2019.08.037.

5. Samano MN, Fernandes LM, Baranauskas JCB, et al. Risk factors and survival impact of primary graft dysfunction after lung transplantation in a single institution. Transplant Proc. 2012;44:2462-8. https://doi.org/10.1016/j.transproceed.2012.07.134.

6. Klesney-Tait J, Eberlein M, Geist L, et al. Starting a lung transplant program: a roadmap for long-term excellence. Chest. 2015;147: 1435-43. https://doi.org/10.1378/chest.14-2241.

7. Fessler J, Davignon M, Sage E, et al. Intraoperative implications of the recipients' disease for double-lung transplantation. J Cardiothorac Vasc Anesth. 2021;35:530-8. https://doi.org/10.1053/j.jvca.2020. 07.039 .

8. Martin AK, Fritz AV, Wilkey BJ. Anesthetic management of lung transplantation: impact of presenting disease. Curr Opin Anaesthesiol. 2020;33:43-9. https://doi.org/10.1097/ACO. 0000000000000805.

9. Stehlik J, Stevenson LW, Edwards LB, et al. Organ allocation around the world: insights from the ISHLT International Registry for Heart and Lung Transplantation. J Heart Lung Transplant. 2014;33:97584. https://doi.org/10.1016/j.healun.2014.08.001.

Publisher's note Springer Nature remains neutral with regard to jurisdictional claims in published maps and institutional affiliations. 